Grisel Lopez, MD*

Jenny Kim, BA*

Edythe Wiggs, PhD

Dahima Cintron, BS

Catherine Groden, CRNP

Nahid Tayebi, PhD

Pramod K. Mistry, MD

Gregory M. Pastores, MD

Ari Zimran, MD

Ozlem Goker-Alpan, MD

Ellen Sidransky, MD

Correspondence to

Dr. Sidransky:

sidranse@mail.nih.gov

\title{
Clinical course and prognosis in patients with Gaucher disease and parkinsonism
}

\section{OPEN}

ABSTRACT

Objective: The goal of this study was to characterize the parkinsonian phenotype in patients with Gaucher disease (GD) who developed parkinsonism in order to evaluate clinical course and prognosis.

Methods: This is a retrospective observational study conducted at the Clinical Center of the $\mathrm{NIH}$, Bethesda, MD, over a period of 10 years. The study included 19 patients with GD and parkinsonism. The severity of Gaucher and parkinsonian symptoms was determined from clinical data including physical, neurologic, pathologic, and neurocognitive evaluations, family histories, imaging studies, olfactory testing, and validated questionnaires.

Results: We found an earlier age at onset of parkinsonism and evidence of mild cognitive dysfunction in our cohort. Although the clinical course in some patients was similar to that of idiopathic Parkinson disease with a favorable levodopa response, others exhibited features characteristic of dementia with Lewy bodies. When we examined the patients as a group, we did not observe a uniformly aggressive form of parkinsonism after the initial onset of symptoms, contrary to other published reports.

Conclusions: Appreciable clinical variation was seen in this cohort with GD and parkinsonism. Although some patients had early onset and prominent cognitive changes, others had a later, slower course, indicating that GBA1 mutations may not be a reliable prognostic indicator in Parkinson disease in clinical settings. Neurol Genet 2016;2:e57; doi: 10.1212/ NXG.0000000000000057

\section{GLOSSARY}

$\mathbf{A A D}=$ age at death; $\mathbf{A A O}=$ age at onset; $\mathbf{B V M T}-\mathbf{R}=$ Brief Visuospatial Memory Test-Revised; $\mathbf{C O D}=$ cause of death; $\mathbf{D L B}=$ dementia with Lewy bodies; ERT = enzyme replacement therapy; GCase = glucocerebrosidase; GD = Gaucher disease; iPD = idiopathic Parkinson disease; PD = Parkinson disease; UPDRS = Unified Parkinson's Disease Rating Scale; UPSIT = University of Pennsylvania Smell Identification Test.

The association between the lysosomal enzyme glucocerebrosidase (GCase) and parkinsonism has radically influenced research in this field. Hints of this relationship came from sporadic cases $^{1}$ and small cohorts of patients with Gaucher disease (GD) and Parkinson disease (PD). ${ }^{2-6}$ Family histories revealed that even heterozygosity for glucocerebrosidase (GBA1) mutations was associated with PD. ${ }^{7}$ A multicenter analysis including more than 5,000 patients with $\mathrm{PD}$ and controls unequivocally demonstrated that patients were over 5.43 times more likely to carry a $G B A 1$ mutation, rendering mutations in $G B A 1$ the most common genetic risk factor for parkinsonism. ${ }^{8,9}$ Similar associations were also reported between $G B A 1$ mutations and both dementia with Lewy bodies (DLB) ${ }^{10}$ and multiple system atrophy, ${ }^{11}$ emphasizing the role of the lysosome in the pathogenesis of these neurodegenerative diseases.

\footnotetext{
*These authors contributed equally to the manuscript.

From the Section on Molecular Neurogenetics (G.L., J.K., E.W., D.C., C.G., N.T., O.G.-A., E.S.), Medical Genetics Branch, NHGRI, NIH, Bethesda, MD; Yale School of Medicine (P.K.M.), New Haven, CT; Mater Misericordiae University Hospital (G.M.P.), Dublin, Ireland; Gaucher Clinic (A.Z.), Shaare Zedek Medical Center, Hebrew University-Hadassah Medical School, Jerusalem, Israel; and Lysosomal Disorders Research \& Treatment Unit (O.G.-A.), O \& O Alpan LLC, Fairfax, VA.

Funding information and disclosures are provided at the end of the article. Go to Neurology.org/ng for full disclosure forms. The Article Processing Charge was paid by the NHGRI.

This is an open access article distributed under the terms of the Creative Commons Attribution-NonCommercial-NoDerivatives License 4.0 (CC BY-NC-ND), which permits downloading and sharing the work provided it is properly cited. The work cannot be changed in any way or used commercially.
} 
PD affects approximately $2 \%$ of the population by age $70 .{ }^{12}$ It is characterized by bradykinesia in addition to tremor, rigidity, and/ or postural instability.

GD is caused by mutations in GBA1 resulting in deficient GCase in lysosomes and glycolipid storage in macrophages. The disorder often manifests with hepatosplenomegaly, skeletal involvement, anemia, and thrombocytopenia. Although only a minority of patients ultimately develop PD, characterization of these patients may help to elucidate the mechanisms underlying this association and potential prognostic indicators.

We describe 19 patients with homozygous or compound heterozygous mutations in $G B A 1$ with parkinsonism, aiming to characterize the disease phenotype and prognosis in this population.

METHODS This is primarily a retrospective observational study of 19 patients with GD and parkinsonian manifestations. The clinical diagnosis of GD was confirmed by low GCase activity in leukocytes or fibroblasts ${ }^{13}$ and/or molecular analysis by full GBA1 sequencing. ${ }^{14}$ Seventeen patients were evaluated at the $\mathrm{NIH}$, and patients had follow-up evaluations between 0 and 10 years after the initial visit. The remaining 2 patients were autopsied at the Clinical Center at the NIH and clinical records were provided. Several of the patients included were previously reported in the literature without longitudinal follow-up. ${ }^{15}$ All patients had a diagnosis of PD or DLB that was made based on the UK Parkinson Disease Society Brain Bank clinical diagnostic criteria ${ }^{16}$ or DLB criteria, ${ }^{17}$ respectively. Clinical data describing GD clinical manifestations and PD clinical course and outcome were determined by review of medical records and longitudinal evaluations when possible. These data included family history, physical and neurologic evaluations, neurocognitive testing, imaging studies, and laboratory parameters. Part III of the Unified Parkinson's Disease Rating Scale (UPDRS-III) was used to assess the severity of motor symptoms ( $\mathrm{n}=11$ in the "on" state and $\mathrm{n}=5$ in both the "on" and "off" states). ${ }^{18}$ Patients were examined by a single neuropsychologist who performed a consistent battery of tests during each visit for the majority of patients $(n=12)$. The intellectual domains evaluated include memory, verbal and nonverbal reasoning, processing speed, focus/attention, and visuospatial skills. However, not all subtests could be administered in every patient. The University of Pennsylvania Smell Identification Test (UPSIT) was used to test olfactory function $(n=10)$; scores were adjusted for age and sex. ${ }^{19}$ Autopsy reports, when available, were also reviewed $(n=5)$. Unfortunately, not all of these evaluations were available for each patient, but because of the rarity of patients sharing the 2 diagnoses, we included as much clinical data as possible.

Standard protocol approvals, registrations, and patient consents. The National Human Genome Research Institute Institutional Review Board at the NIH approved the study (clinical trial identifier number NCT00001215). All participants or their legal representatives provided written informed consent.
The protocol consent explicitly stated that participation was entirely voluntary and that if enrolled, a study participant could withdraw from the study at any time.

RESULTS The genotypes and Gaucher clinical features of the 19 patients (10 male and 9 female) are summarized in table 1 . Consistent with the clinical history of GD, a vast spectrum of systemic manifestations was observed. Although the cohort was genotypically heterogeneous, most patients carried at least 1 N370S allele. Nine of 19 patients (47.4\%) were homozygous for N370S. Only 1 patient (genotype L444P/D409H) had a diagnosis of GD type 3 based on slowed horizontal saccades. ${ }^{6}$ The mean age at onset (AAO) of Gaucher symptoms was 27.6 years with a median of 24 years and a range of 4 to 61 years. The mean duration between symptom onset and most recent evaluation was 26.6 years with a median of 26 years and a range of 5 to 60 years (table 2). In most patients, the presenting manifestations were an enlarged spleen and/or liver or hematologic abnormalities. Eight of the 19 patients (42.1\%) had undergone splenectomy. The majority of patients (14 of 19 [73.7\%]) received enzyme replacement therapy (ERT) with recombinant GCase, and most started the therapy many years before the onset of parkinsonian manifestations (table 3). Skeletal involvement, especially osteoporosis, was common in this cohort. In addition, 9 of 19 patients (47.4\%) experienced either avascular necrosis of one or both hips or spontaneous fractures.

The parkinsonian phenotype (table 3) was also diverse. The mean AAO of symptoms was 49.7 years with a median of 50 years and a range of 33 to 64 years (table 2). In the majority of patients, a unilateral rest tremor was the initial presenting sign. The classical parkinsonian motor features-tremor, bradykinesia, rigidity, and gait problems - became prevalent as the disease progressed. The 15 patients who received dopaminergic therapy reported at least some positive response. Olfactory function was assessed using the UPSIT in 10 patients at the time of evaluation (table 3). The average UPSIT score was 19.3 (a normal score is $>35$ of 40 items) and the median was 19, indicating severe microsmia in this cohort (table 2).

In a subgroup of patients, the severity of motor dysfunction was assessed with the UPDRS-III, which has a maximum score of 108 ; higher numbers indicate more motor impairment (table 3). For the 11 patients tested, the average "on" score was 26.9 with a median of 29. Of these 11 patients, 5 were also evaluated in the "off" state and showed an average motor improvement of $\sim 19.1 \%$ with levodopa therapy.

Neuropsychiatric symptoms were commonly reported in this cohort (table 3). The most prevalent 


\begin{tabular}{|c|c|c|c|c|c|c|c|c|}
\hline Patient, sex & Ethnicity & Genotype & $\begin{array}{l}\text { Age at onset of } \\
\text { symptoms, } y\end{array}$ & Initial presentation & Findings & Splenectomy & ERT & $\begin{array}{l}\text { Age at } \\
\text { death, } \\
y\end{array}$ \\
\hline Patient 1, F & AJ & N370S/L444P & 29 & Thrombocytopenia & Mild osteopenia, minimal Erlenmeyer flask deformity, HSM & No & No & - \\
\hline Patient 2, F & French/English & N370S/L444P & 17 & Splenomegaly & $\begin{array}{l}\text { Kidney tumor in } 2000 \text {, history of absence seizures, spontaneous } \\
\text { fracture of ribs, Erlenmeyer flask deformity, osteopenia }\end{array}$ & Yes, at age 18 & Yes & 70 \\
\hline Patient 3, F & AJ & N370S/IVS $2+1$ & 5 & HSM, bone crisis & AVN of the right hip & Yes, at age 14 & Yes & - \\
\hline Patient 4, M & Irish & N370S/N370S & 47 & Brother diagnosed & Osteoporosis, spontaneous vertebral fracture, abnormal EEG & No & No & - \\
\hline Patient 5, F & AJ & N370s/rec & 24 & $\begin{array}{l}\text { Splenomegaly, } \\
\text { thrombocytopenia }\end{array}$ & Osteoporosis, liver enzyme abnormalities & Yes, at age 30 & Yes & - \\
\hline Patient 6, M & AJ & N370S/c.84insG & 12 & Bone crisis & 6-7 blackout episodes daily of unknown etiology, osteoporosis & Yes, at age 12 & Yes & 59 \\
\hline Patient 7, M & Italian & N370S/N370S & 24 & $\mathrm{AVN}$ of the right femur & AVN of the right hip, mild HSM & No & Yes & - \\
\hline Patient 8, F & AJ & N370S/N370s & 4 & HSM & AVN of the right hip, Erlenmeyer flask deformity & No & Yes & - \\
\hline Patient 9, M & AJ & N370S/N370S & 48 & Thrombocytopenia, fatigue & Osteoporosis & No & Yes & 62 \\
\hline Patient 10, M & AJ & N370S/N370S & 33 & HSM, CMV infection & HSM, mild osteopenia, thrombocytopenia & No & No & 59 \\
\hline Patient 11, M & NA & N370S/R257Q & 31 & $\begin{array}{l}\text { Thrombocytopenia but bone } \\
\text { crisis since age } 4\end{array}$ & AVN of the right hip (replaced), splenomegaly & No & Yes & - \\
\hline Patient 12, F & Scottish & N370S/55bpdel & 16 & $\begin{array}{l}\text { Splenomegaly, nosebleeds, } \\
\text { bone crisis }\end{array}$ & Osteopenia, spinal surgery, restless legs syndrome & Yes & Yes & - \\
\hline Patient 13, M & AJ & N370S/N370s & 26 & Splenomegaly & $\begin{array}{l}\text { Marrow involvement, AVN of the left femoral head, cortical } \\
\text { renal cysts }\end{array}$ & Yes, at age 26 & Yes & - \\
\hline Patient 14, F & Irish/English & L444P/D409H & 19 & HSM & 11-lb spleen, osteopenia, abnormal EEG & Yes, at age 34 & Yes & 53 \\
\hline Patient 15, M & AJ & N370S/N370S & 61 & Thrombocytopenia & Osteopenia, splenomegaly & No & No & 76 \\
\hline Patient 16, M & AJ & N370S/N370S & 47 & HSM, thrombocytopenia & Osteoporosis, splenomegaly, abnormal EEG & No & Yes & 73 \\
\hline Patient 17, F & AJ & N370S/c.84insG & 14 & Bone crisis since age 10 & Bilateral hip replacement, severe bone pain, liver involvement & Yes, at age 18 & Yes & 61 \\
\hline Patient 18, M & AJ & N370S/V394L & 20 & Low platelets, anemia & Pain crises, osteopenia & No & No & - \\
\hline Patient 19, F & AJ & N370S/N370S & 47 & $\begin{array}{l}\text { Anemia, vasculitis of legs, } \\
\text { polyclonal gammopathy }\end{array}$ & $\begin{array}{l}\text { Osteopenia, thrombocytopenia, mild hepatosplenomegaly, AVN } \\
\text { of the right hip (replaced), severe disc disease, lymphocytic } \\
\text { interstitial pneumonitis, renal failure }\end{array}$ & No & Yes & 73 \\
\hline
\end{tabular}




\begin{tabular}{|c|c|c|c|}
\hline \multirow[t]{2}{*}{ Table 2} & \multicolumn{3}{|c|}{$\begin{array}{l}\text { Quantitative measures related to Gaucher disease and/or } \\
\text { parkinsonism }\end{array}$} \\
\hline & & Average & Median \\
\hline \multicolumn{2}{|c|}{ Age at onset of GD symptoms, y $(n=19)$} & 27.6 & 24 \\
\hline \multicolumn{2}{|c|}{ Length of time followed since GD diagnosis, $y(n=19)$} & 26.6 & 26 \\
\hline \multicolumn{2}{|c|}{ Age at PD onset, y $(n=19)$} & 49.7 & 50 \\
\hline \multicolumn{2}{|c|}{ UPSIT score (of 40$)(n=10)^{a}$} & 19.3 & 19 \\
\hline \multicolumn{2}{|c|}{ Age at death, y $(n=9)$} & 65.1 & 62 \\
\hline
\end{tabular}

Abbreviations: GD = Gaucher disease; PD = Parkinson disease; UPSIT = University of Pennsylvania Smell Identification Test.

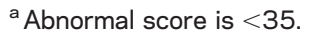

at death (AAD), PD duration, and cause of death (COD), when known, for all 9 patients. For these patients, the average PD duration was 11.1 years with a median of 11 years. The average AAD was 65.1 years with a median of 62 years. The COD was unknown for patients 10 and 16. Three patients died of aspiration pneumonia. Other CODs included acute pyelonephritis, intractable infected decubitus ulcers, complications from cardiac surgery, and multiorgan failure with terminal pneumonia. Five autopsy studies were performed. Three patients were pathologically confirmed as having DLB and 2 others met pathologic criteria for PD.

Although our numbers are extremely limited, we attempted to explore whether the parkinsonian features correlated with the $G B A 1$ genotype by comparing patients with genotype N370S/N370S with those with N370S/other. The 9 N370S homozygotes had a mean $\mathrm{AAO}$ of GD of 37.4 years vs 18.6 years in those with N370S/other, indicating that, as expected, the non-N370S allele correlated with more severe systemic disease. Among the deceased patients, the 5 N370S homozygotes had a mean duration of PD of 11.8 years, whereas the 3 N370S compound heterozygotes had a mean duration of 9.6 years. These preliminary observations require substantiation with a larger group of patients in each cohort.

DISCUSSION Our phenotypic characterization of these 19 patients with GD and parkinsonism provides insight into the parkinsonian spectrum associated with GBA1 mutations. Consistent with smaller published studies, we generally observed an earlier AAO of PD symptoms in these patients (mean 49.7 years) compared with the mean AAO of 62.4 years seen in patients with idiopathic Parkinson disease (iPD) ${ }^{20}$ and the mean AAO of 54.9 years seen in GBA1 heterozygotes with $\mathrm{PD} .{ }^{8}$ In this study, the mean $\mathrm{PD}$ duration in the deceased individuals was 11.1 years, which is 2 years shorter than the mean PD duration of 13.1 years reported with iPD. ${ }^{20}$ However, many factors may contribute to this finding. The clinical course of the 10 surviving patients in the cohort and their current length of disease duration demonstrate that the PD duration can be longer in some individuals. Also, 4 of the deceased patients had parkinsonism for 12 to 15 years. In addition, this cohort, like others reported in the literature, includes patients who met the diagnostic criteria for synucleinopathies other than PD. This heterogeneity complicates interpretation of the findings because the different synucleinopathies are characterized by different AAO and disease duration, so an average may not be a clinically useful measure. For example, disease duration and survival of patients with DLB tends to be shorter than in patients with PD (range 5-7 years ${ }^{21}$ ), and this could be a confounding factor in data analysis. 


\begin{tabular}{|c|c|c|c|c|c|c|c|c|c|c|c|c|}
\hline Table 3 & arkinsonia & an features & & & & & & & & & & \\
\hline \multirow[b]{2}{*}{ Patient, sex } & \multirow{2}{*}{$\begin{array}{l}\text { Age at } \\
\text { onset, } y\end{array}$} & \multirow{2}{*}{$\begin{array}{l}\text { Clinical } \\
\text { diagnosis }\end{array}$} & \multirow[b]{2}{*}{ Presenting features } & \multirow[b]{2}{*}{ Other motor symptoms } & \multirow[b]{2}{*}{ Mood disturbances } & \multirow{2}{*}{$\begin{array}{l}\text { Dopaminergic } \\
\text { therapy }\end{array}$} & \multirow{2}{*}{$\begin{array}{l}\text { UPSIT } \\
\text { score } \\
\text { (of } 40 \text { ) }\end{array}$} & \multirow{2}{*}{$\begin{array}{l}\text { ERT duration } \\
\text { before PD } \\
\text { onset, y }\end{array}$} & \multicolumn{2}{|c|}{$\begin{array}{l}\text { UPDRS-III } \\
\text { score (of 108) }\end{array}$} & \multirow{2}{*}{$\begin{array}{l}\text { Age at death, } \\
\text { y/disease } \\
\text { duration, } y\end{array}$} & \multirow{2}{*}{ Cause of death } \\
\hline & & & & & & & & & On & Off & & \\
\hline Patient 1, F & 48 & PD & Stiffness on left & $\begin{array}{l}\text { Rest tremors, } \\
\text { bradykinesia, balance } \\
\text { problems }\end{array}$ & $\begin{array}{l}\text { Depression, anxiety, panic } \\
\text { episodes }\end{array}$ & NT & 24 & NT & - & 29 & - & - \\
\hline Patient 2, F & 60 & PD & $\begin{array}{l}\text { Rest tremor of right hand, } \\
\text { wrist, and foot }\end{array}$ & $\begin{array}{l}\text { Rigidity, bradykinesia, } \\
\text { shuffling gait, balance } \\
\text { problems, falls }\end{array}$ & Anxiety, fugue episodes & Yes & 26 & 9 & 33 & 41 & $70 / 10$ & Acute pyelonephritis \\
\hline Patient 3, F & 44 & $\begin{array}{l}\text { Functional } \\
\text { tremor }\end{array}$ & $\begin{array}{l}\text { Rest tremor of left } \\
\text { leg, bradykinesia }\end{array}$ & $\begin{array}{l}\text { Uses crutches, antalgic } \\
\text { gait, slouched posture }\end{array}$ & Anxiety & NT & 19 & 23, interrupted & - & 40 & - & - \\
\hline Patient 4, M & 52 & PD & $\begin{array}{l}\text { Rest tremor of left } \\
\text { hand, bradykinesia }\end{array}$ & $\begin{array}{l}\text { Rigidity, shuffling gait, } \\
\text { freezing gait, falls }\end{array}$ & $\begin{array}{l}\text { Hallucinations, depression, } \\
\text { anxiety }\end{array}$ & Yes & 11 & NT & 36 & NA & - & - \\
\hline Patient 5, F & 52 & PD & Gait problems & $\begin{array}{l}\text { Dystonic dyskinesia, } \\
\text { rigidity, shuffling gait, } \\
\text { start hesitation }\end{array}$ & Hallucinations & Yes & NA & 6 & 23 & NA & - & - \\
\hline Patient 6, M & 45 & DLB & $\begin{array}{l}\text { Rest tremor of right } \\
\text { hand, soft speech }\end{array}$ & $\begin{array}{l}\text { Bradykinesia, rigidity, } \\
\text { myoclonus, freezing, } \\
\text { shuffling gait, balance } \\
\text { problems }\end{array}$ & $\begin{array}{l}\text { Psychosis, hallucinations, } \\
\text { blackout episodes, anxiety }\end{array}$ & Yes & NA & 2 & NA & 36 & $59 / 14$ & Aspiration pneumonia \\
\hline Patient 7, M & 37 & PD & $\begin{array}{l}\text { Rest tremor of right } \\
\text { hand and leg }\end{array}$ & Rigidity, cramps, pain & Depression, anxiety & NT & 34 & 9 & NA & 8 & - & - \\
\hline Patient 8, F & 33 & PD & $\begin{array}{l}\text { Left leg, neck, and } \\
\text { shoulder pain }\end{array}$ & $\begin{array}{l}\text { Rest tremors, dystonia, } \\
\text { rigidity, movement arrest }\end{array}$ & None & Yes & NA & 17 & 9 & NA & - & - \\
\hline Patient 9, M & 53 & DLB & $\begin{array}{l}\text { Rest tremor of right } \\
\text { hand }\end{array}$ & $\begin{array}{l}\text { Rigidity, dyskinesia, } \\
\text { shuffling gait, } \\
\text { propulsion, balance } \\
\text { problems }\end{array}$ & $\begin{array}{l}\text { Hallucinations, panic } \\
\text { attacks, depression, } \\
\text { anxiety, anhedonia }\end{array}$ & Yes & 25 & 1 & 36 & 36 & $62 / 10$ & $\begin{array}{l}\text { Intractable infected } \\
\text { decubitus ulcers }\end{array}$ \\
\hline Patient 10, M & 50 & PD vs DLB & $\begin{array}{l}\text { Rest tremor of left hand, } \\
\text { fatigue }\end{array}$ & $\begin{array}{l}\text { Rigidity, dyskinesia, } \\
\text { bradykinesia, shuffling } \\
\text { gait, balance problems }\end{array}$ & Depression, anxiety & Yes & 19 & NT & 27 & 30 & $59 / 10$ & Unknown \\
\hline Patient 11, M & 46 & PD & Rest tremor of right leg & $\begin{array}{l}\text { Rigidity, numbness, } \\
\text { dyskinesia, dystonia }\end{array}$ & Anxiety, hallucinations & Yes & NA & 13 & NA & 29 & - & - \\
\hline Patient 12, F & 59 & PD & Rest tremor of left leg & $\begin{array}{l}\text { Rigidity, bradykinesia, } \\
\text { stooped posture, falls }\end{array}$ & $\begin{array}{l}\text { Hallucinations, anger, } \\
\text { tearfulness }\end{array}$ & NT & NA & 18 & NA & 18 & - & - \\
\hline Patient 13, M & 40 & PD & $\begin{array}{l}\text { Rest tremor of right } \\
\text { hand and wrist, } \\
\text { stiffness }\end{array}$ & $\begin{array}{l}\text { Bradykinesia, stiffness, } \\
\text { masked facies, balance } \\
\text { problems }\end{array}$ & $\begin{array}{l}\text { Depression, anxiety, } \\
\text { irritability }\end{array}$ & Yes & 11 & $>8$ & 17 & 32 & - & - \\
\hline Patient 14, F & 42 & $\begin{array}{l}\text { PD with } \\
\text { dementia }\end{array}$ & Rest tremor of left hand & $\begin{array}{l}\text { Stiffness, masked } \\
\text { facies, balance problems, } \\
\text { falls }\end{array}$ & Depression, confusion & Yes & NA & 0 & NA & NA & $53 / 12$ & Aspiration pneumonia \\
\hline Patient 15, M & 64 & PD & Rest tremor of right hand & $\begin{array}{l}\text { Rigidity, bradykinesia, } \\
\text { stiffness, shuffling, falls }\end{array}$ & Irritability & Yes & 14 & NT & 34 & 42 & $76 / 13$ & $\begin{array}{l}\text { Complications from } \\
\text { cardiac surgery }\end{array}$ \\
\hline
\end{tabular}

Continued 
Although PD and DLB have overlapping pathologic findings, the 2 disorders have important clinical differences and present distinct clinical challenges. For example, because patients with DLB have psychotic features and hallucinations, the use of dopaminergic medications is of great concern in this population. ${ }^{21}$ The inclusion of patients with different synucleinopathies will also skew generalizations regarding levodopa response, as patients with DLB have a more limited response to dopaminergic therapy. ${ }^{22}$ Thus, a poorer prognosis does not necessarily apply to all patients with $G B A 1$-associated parkinsonism but will greatly depend on the specific underlying pathologic mechanism. However, given the small sample size, we could not perform subgroup analyses to establish the contribution of the inclusion of patients ultimately found to have DLB to the overall findings.

The UPDRS-III score is the most widely used measure to assess motor function in patients with parkinsonism, and the average "on" score of 26.9 for the 11 patients assessed does identify impairment. Although there is variation in therapeutic response to L-dopa, patients with iPD usually have an improvement of $20 \%$ to $70 \%$ in their motor symptoms, ${ }^{23}$ especially early in the disease course. The small subgroup of patients who were tested in both "on" and "off" states had an average response of $19.1 \%$ to L-dopa therapy, which is relatively low, and the interpretation of this finding can be complicated by several factors. First, many of these patients had a diagnosis of parkinsonism several years before their evaluation at the NIH and may have developed motor fluctuations and a more limited response to levodopa associated with disease progression. Second, the fact that some patients had a DLB phenotype likely contributes to the limited response seen in the group as a whole. Third, the orthopedic and mobility problems sometimes encountered in patients with GD could contribute to higher motor scores on specific items on the UPDRS-III.

In addition to motor symptoms, it is now understood that patients with iPD have a wide range of nonmotor features, often many years before motor manifestations. ${ }^{24}$ These nonmotor manifestations, including cognitive impairment, olfactory dysfunction, and sleep and neuropsychiatric disturbances, are experienced by a majority of patients with iPD at some point during their disease course and contribute to decreased independence in activities of daily living and increased emotional burden. ${ }^{25}$

Many of the patients in our cohort demonstrated some form of cognitive impairment, especially in memory and processing speed (table 4), although not all patients performed poorly. Decision-making, visuospatial abilities, and attention were preserved in 


\begin{tabular}{|c|c|c|c|c|}
\hline Table $4 \quad$ Neurocognitive testing & & & & \\
\hline Test & Mean score & Median score & Z-score & Percentile \\
\hline Similarities $(\mathrm{n}=11)^{\mathrm{a}}$ & 10.4 & 10 & 0.07 & 50th \\
\hline Block Design $(n=12)^{a}$ & 8.7 & 8.5 & -0.67 & 25th \\
\hline Digit Span $(n=8)^{a}$ & 9.2 & 9.5 & -0.33 & 37 th \\
\hline Hopkins Immediate Memory $(n=7)^{b}$ & 30.6 & 24 & -2 & 2nd \\
\hline Hopkins Delayed Memory $(n=7)^{b}$ & 33.4 & 33 & -1.7 & 4 th \\
\hline Brief Visuospatial Memory Test-Revised Immediate Memory $(n=8)^{b}$ & 31.6 & 27 & -1.8 & 3rd \\
\hline Brief Visuospatial Memory Test-Revised Delayed Memory $(n=8)^{b}$ & 31 & 28 & -1.9 & 3rd \\
\hline Digit Symbol Coding $(n=12)^{a}$ & 7.8 & 6.5 & -0.84 & 20th \\
\hline Symbol Search $(n=10)^{a}$ & 8 & 7.5 & -0.67 & 25th \\
\hline
\end{tabular}

many patients even though these cognitive domains are frequently affected in patients with Parkinsonassociated dementia, ${ }^{26}$ hinting that a different mechanism might be responsible for cognitive dysfunction in our cohort. Moreover, it suggests that not all patients with GBA1-associated parkinsonism are destined to develop dementia, which highlights the need to proceed with caution when counseling patients and their families about the probability of severe cognitive dysfunction early in the disease process. Some patients may have a very similar disease progression to that seen in iPD. More generally, evaluations of cognitive function in patients with GBA1associated parkinsonism showed stronger verbal than nonverbal abilities, similar to what has been reported in patients with iPD.

Studies of iPD indicate that many of these patients experience varying levels of depression and anxiety at some point during their PD course. Psychotic symptoms and hallucinations are also often seen in iPD, most frequently among patients who are on antiparkinsonian medications, ${ }^{27}$ necessitating close monitoring and careful management of these patients. Almost half of our patients experienced depression. Anxiety and/or panic attacks were seen in $58 \%$ of patients. In addition, $53 \%$ of patients reported psychotic features, most often presenting as hallucinations. Although such mood and psychotic features may be more frequent in this cohort, it is unclear whether they are related to parkinsonism, mutant GCase, or our mixed population of patients with different synucleinopathies. Further exploration of these nonmotor features is necessary.

Pneumonia is a frequent COD among patients with PD. ${ }^{28}$ In this cohort, 3 of the 9 deceased patients died of aspiration pneumonia as an immediate cause. Other CODs included acute pyelonephritis and sepsis, also common in the elderly population and in patients with mobility issues.
Other smaller studies have examined specific disease manifestations in patients with GD who developed parkinsonism. In a study from Israel of 11 patients with both disorders, an earlier AAO of parkinsonism, more frequent cognitive problems, and more frequent and earlier complications from levodopa therapy, including motor fluctuations and dyskinesias, were noted. In a study of 10 patients with GD and PD from the French national Gaucher disease registry pooled with 49 cases of GD and PD taken from the literature, it was noted that these patients exhibited a poorer response to L-dopa therapy when compared with patients with iPD. ${ }^{29}$ However, at this time, no specific phenotypic presentation is unique to patients with parkinsonism who carry GBA1 mutations. A study of 4 patients with both GD and PD identified from a tertiary Parkinson center described prominent neuropsychiatric problems, anosmia, as well as hyperechogenicity of the substantia nigra on ultrasound and presynaptic dopaminergic cell loss on PET, all of which are seen in patients with iPD. ${ }^{30}$ Of note, all 4 patients were diagnosed with GD only after the development of PD.

In contrast to reports that $G B A 1$-associated parkinsonism is uniformly associated with a more aggressive course, our 19 patients exhibited an array of Gaucher manifestations, PD symptoms, and nonmotor manifestations. This heterogeneity in patients with a rare disorder and an even rarer comorbidity needs to be taken into consideration, especially because the majority of patients with GD and GBA1 mutation carriers never develop parkinsonism. The published literature is confusing: in 1 study of American patients with GD type 1, those who developed parkinsonism had higher scores on the GD Severity Score Index and Hermann score, ${ }^{31}$ whereas in a study from the global International Collaborative Gaucher Group Gaucher Registry, patients who developed parkinsonism had a milder 
Gaucher phenotype than those without PD. ${ }^{32}$ Thus, even within this very specific subset of patients, there are complexities and nuances in the disease presentation and course, rendering it difficult to make generalizations about all patients with GD and PD. It is also unknown whether chronic therapy with ERT will alter (increase or decrease) the risk of developing PD in the future.

In addition to the small sample size, one limitation of this study is that it was conducted at a tertiary referral center. It is possible that patients with GD and PD with more severe manifestations might have been unable or unwilling to travel to the NIH, and this may be a source of bias in recruitment.

Further characterization of patients with both GD and parkinsonism will continue to provide insight into our understanding of the relationship between the 2 disorders. Clarification of the prognostic indicators for each is of value to patients and caregivers as they consider lifestyle changes as both diseases progress. Although this study is limited by the small cohort size, we identify issues to consider when deliberating prognosis and treatment for patients with GBA1-associated parkinsonism. Standardized clinical outcome measures, longitudinal follow-up of at-risk individuals, and pathologic confirmation of clinical diagnosis will greatly enhance our ability to identify pathophysiologic mechanisms underlying disease onset and progression, discover useful clinical biomarkers, and develop preventive treatments for PD.

\section{AUTHOR CONTRIBUTIONS}

Ellen Sidransky had full access to all of the data in the study and takes responsibility for the integrity of the data and the accuracy of the data analysis. Grisel Lopez, Jenny Kim, and Ellen Sidransky designed the study, analyzed data, and wrote the manuscript. Edythe Wiggs performed the neurocognitive testing and interpreted the data, Dahima Cintron analyzed clinical data, Nahid Tayebi performed the patient genotyping and interpreted the results, and Ozlem Goker-Alpan, Pramod K. Mistry, Gregory M. Pastores, Ari Zimran, and Catherine Groden were involved in conceptualization of the study, patient care, and the interpretation of clinical data.

\section{ACKNOWLEDGMENT}

The authors acknowledge the help of the Departments of Pathology at the NIH Clinical Center and Yale University School of Medicine and the editing assistance of Nina Monestime.

\section{STUDY FUNDING}

The work of Grisel Lopez, Jenny Kim, Edythe Wiggs, Dahima Cintron, Catherine Groden, Nahid Tayebi, and Ellen Sidransky was supported by the Intramural Research Programs of the National Human Genome Research Institute and the NIH. Pramod K. Mistry is supported by NIH-NIAMS 65932. His research is also supported by Center of Excellence Grant in Clinical Translational Research in Gaucher disease. Ari Zimran's clinic receives grant support from Genzyme and Shire for participation in their Gaucher disease registries.

\section{DISCLOSURE}

Grisel Lopez, Jenny Kim, Edythe Wiggs, Dahima Cintron, Catherine Groden, and Nahid Tayebi report no disclosures. Pramod K. Mistry has received honoraria for lectures and consulting fees from Genzyme, has served on the scientific advisory board of DSMB of acute liver failure study group (PALF) NIH, and has received research support from Genzyme-Sanofi and NIH. Gregory M. Pastores has received honoraria for consultation and advisory board participation from BioMarin, Genzyme (Sanofi), Pfizer, and Shire and has served on the editorial boards of Orphanet and JIMD. Ari Zimran is a consultant to Protalix BioTherapeutics, is a member of its scientific advisory board, and has stock options with the company; has received speaker honoraria and travel expenses from Shire, Genzyme-Sanofi, and Pfizer; has served on the editorial board of Blood Cells, Molecules and Diseases; and has been on the speakers' bureaus of Pfizer, Genzyme-Sanofi, and Shire. Ozlem GokerAlpan is on the scientific advisory boards of Shire, Genzyme, BioMarin, Amicus, Pfizer, and Protalix BioTherapeutics; is involved in clinical studies or trials sponsored by Shire, Genzyme, Protalix, Alexion, and Amicus; receives research support from Shire, Genzyme, Actelion, and Pfizer; has received travel funding/speaker honoraria from Genzyme, Shire, Pfizer, Actelion, and the National Gaucher Foundation; receives consulting fees from Shire, Genzyme, Pfizer, BioMarin, Amicus, Protalix BioTherapeutics, and Actelion; has been an employee of $\mathrm{O} \& \mathrm{O}$ Alpan LLC; and has been on the speakers' bureaus of Genzyme, Shire, Pfizer, and Actelion. Ellen Sidransky has served on the medical advisory board of the National Gaucher Foundation; has served on the editorial board of Molecular Genetics and Metabolism; and has received research support from NIH, NHGRI, and Merck under a Collaborative Research Agreement with NHGRI. Go to Neurology.org/ng for full disclosure forms.

Received September 16, 2015. Accepted in final form January 5, 2016.

\section{REFERENCES}

1. McKeran RO, Bradbury P, Taylor D, Stern G. Neurological involvement in type 1 (adult) Gaucher's disease. J Neurol Neurosurg Psychiatry 1985;48:172-175.

2. Neudorfer O, Giladi N, Elstein D, et al. Occurrence of Parkinson's syndrome in type I Gaucher disease. QJM 1996;89:691-694.

3. Machaczka M, Rucinska M, Skotnicki AB, Jurczak W. Parkinson's syndrome preceding clinical manifestation of Gaucher's disease. Am J Hematol 1999;61:216217.

4. Tayebi N, Callahan M, Madike V, et al. Gaucher disease and parkinsonism: a phenotypic and genotypic characterization. Mol Genet Metab 2001;73:313-321.

5. Itokawa K, Tamura N, Kawai N, Shimazu K, Ishii K. Parkinsonism in type I Gaucher's disease. Intern Med 2006; 45:1165-1167.

6. Tayebi N, Walker J, Stubblefield B, et al. Gaucher disease with parkinsonian manifestations: does glucocerebrosidase deficiency contribute to a vulnerability to parkinsonism? Mol Genet Metab 2003;79:104-109.

7. Goker-Alpan O, Schiffmann R, LaMarca ME, Nussbaum RL, McInerney-Leo A, Sidransky E. Parkinsonism among Gaucher disease carriers. J Med Genet 2004; 41:937-940.

8. Sidransky E, Nalls MA, Aasly JO, et al. Multicenter analysis of glucocerebrosidase mutations in Parkinson's disease. N Engl J Med 2009;361:1651-1661.

9. Lesage S, Anheim M, Condroyer C, et al. Large-scale screening of the Gaucher's disease-related glucocerebrosidase gene in Europeans with Parkinson's disease. Hum Mol Genet 2011;20:202-210.

10. Nalls MA, Duran R, Lopez G, et al. A multicenter study of glucocerebrosidase mutations in dementia with Lewy bodies. JAMA Neurol 2013;70:727-735.

11. Mitsui J, Matsukawa T, Sasaki H, et al. Variants associated with Gaucher disease in multiple system atrophy. Ann Clin Transl Neurol 2015;2:417-426. 
12. Pringsheim T, Jette N, Frolkis A, Steeves TD. The prevalence of Parkinson's disease: a systematic review and meta-analysis. Mov Disord 2014;29:1583-1590.

13. Wenger DA, Clark C, Sattler M, Wharton C. Synthetic substrate beta-glucosidase activity in leukocytes: a reproducible method for the identification of patients and carriers of Gaucher's disease. Clin Genet 1978;13: 145-153.

14. Stone DL, Tayebi N, Orvisky E, Stubblefield B, Madike V, Sidransky E. Glucocerebrosidase gene mutations in patients with type 2 Gaucher disease. Hum Mutat 2000;15:181-188.

15. Goker-Alpan O, Lopez G, Vithayathil J, Davis J, Hallett M, Sidransky E. The spectrum of parkinsonian manifestations associated with glucocerebrosidase mutations. Arch Neurol 2008;65:1353-1357.

16. Hughes AJ, Daniel SE, Kilford L, Lees AJ. Accuracy of clinical diagnosis of idiopathic Parkinson's disease: a clinico-pathological study of 100 cases. J Neurol Neurosurg Psychiatry 1992;55:181-184.

17. McKeith IG. Consensus guidelines for the clinical and pathologic diagnosis of dementia with Lewy bodies (DLB): report of the Consortium on DLB International Workshop. J Alzheimers Dis 2006;9(3 suppl): 417-423.

18. Fahn S, Elotion R. UPDRS Program Members. Unified Parkinson's Disease Rating Scale, Vol. 2. Florham Park, NJ: Macmillan Healthcare Information; 1987.

19. Doty RL, Shaman P, Kimmelman CP, Dann MS. University of Pennsylvania Smell Identification Test: a rapid quantitative olfactory function test for the clinic. Laryngoscope 1984;94:176-178.

20. Hughes AJ, Daniel SE, Blankson S, Lees AJ. A clinicopathologic study of 100 cases of Parkinson's disease. Arch Neurol 1993;50:140-148.
21. Mayo MC, Bordelon Y. Dementia with Lewy bodies. Semin Neurol 2014;34:182-188.

22. Molloy S, McKeith IG, O'Brien JT, Burn DJ. The role of levodopa in the management of dementia with Lewy bodies. J Neurol Neurosurg Psychiatry 2005;76:1200-1203.

23. Lees AJ, Hardy J, Revesz T. Parkinson's disease. Lancet 2009;373:2055-2066.

24. Goldman JG, Postuma R. Premotor and nonmotor features of Parkinson's disease. Curr Opin Neurol 2014;27: 434-441.

25. Duncan GW, Khoo TK, Yarnall AJ, et al. Health-related quality of life in early Parkinson's disease: the impact of nonmotor symptoms. Mov Disord 2014;29:195-202.

26. Beitz JM. Parkinson's disease: a review. Front Biosci (Schol Ed) 2014;6:65-74.

27. Akbar U, Friedman JH. Recognition and treatment of neuropsychiatric disturbances in Parkinson's disease. Expert Rev Neurother 2015;15:1053-1065.

28. Sato K, Hatano T, Yamashiro K, et al. Prognosis of Parkinson's disease: time to stage III, IV, V, and to motor fluctuations. Mov Disord 2006;21:1384-1395.

29. Kraoua I, Stirnemann J, Ribeiro MJ, et al. Parkinsonism in Gaucher's disease type 1: ten new cases and a review of the literature. Mov Disord 2009;24:1524-1530.

30. Saunders-Pullman R, Hagenah J, Dhawan V, et al. Gaucher disease ascertained through a Parkinson's center: imaging and clinical characterization. Mov Disord 2010; 25:1364-1372.

31. Bultron G, Kacena K, Pearson D, et al. The risk of Parkinson's disease in type 1 Gaucher disease. J Inherit Metab Dis 2010;33:167-173.

32. Rosenbloom B, Balwani M, Bronstein JM, et al. The incidence of Parkinsonism in patients with type 1 Gaucher disease: data from the ICGG Gaucher Registry. Blood Cells Mol Dis 2011;46:95-102. 


\section{Neurology

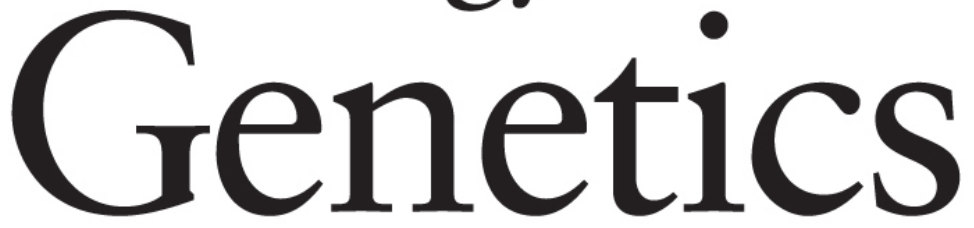

\section{Clinical course and prognosis in patients with Gaucher disease and parkinsonism}

Grisel Lopez, Jenny Kim, Edythe Wiggs, et al.

Neurol Genet 2016;2;

DOI 10.1212/NXG.0000000000000057

\section{This information is current as of March 4, 2016}

\section{Updated Information \& Services}

\section{References}

Subspecialty Collections

Permissions \& Licensing

Reprints including high resolution figures, can be found at: http://ng.neurology.org/content/2/2/e57.full.html

This article cites 31 articles, 4 of which you can access for free at: http://ng.neurology.org/content/2/2/e57.full.html\#\#ref-list-1

This article, along with others on similar topics, appears in the following collection(s):

Dementia with Lewy bodies

http://ng.neurology.org//cgi/collection/dementia_with_lewy_bodies Lipidoses http://ng.neurology.org//cgi/collection/lipidoses

Metabolic disease (inherited)

http://ng.neurology.org//cgi/collection/metabolic_disease_inherited Parkinson's disease/Parkinsonism

http://ng.neurology.org//cgi/collection/parkinsons_disease_parkinsonis $\mathrm{m}$

Information about reproducing this article in parts (figures,tables) or in its entirety can be found online at:

http://ng.neurology.org/misc/about.xhtml\#permissions

Information about ordering reprints can be found online: http://ng.neurology.org/misc/addir.xhtml\#reprintsus

Neurol Genet is an official journal of the American Academy of Neurology. Published since April 2015, it is an open-access, online-only, continuous publication journal. Copyright $\odot 2016$ American Academy of Neurology. All rights reserved. Online ISSN: 2376-7839.

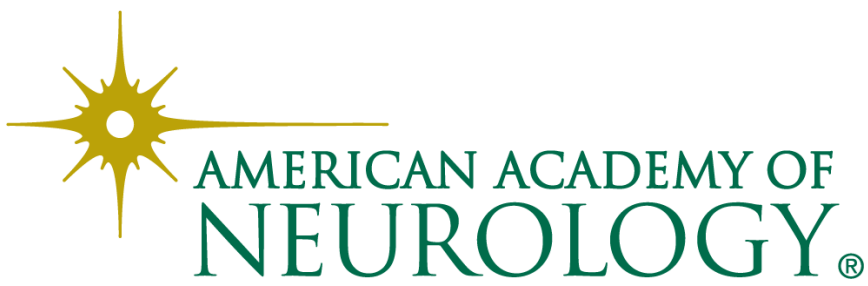

